\title{
Sensory Design of Learning Environment for Autism: Architects awareness?
}

\section{Roslinda Ghazali1, Siti Rasidah Md. Sakip2,4, Ismail Samsuddin ${ }^{3}$}

${ }^{1}$ Department of Post-graduate, ${ }^{2}$ Department of Landscape Architecture, ${ }^{3}$ Department of Architecture,Faculty of Architecture, Planning \& Surveying, Universiti Teknologi MARA Perak Branch, Seri Iskandar Campus, 32610, Perak, Malaysia

${ }^{4}$ Green Safe Cities Research Group, Universiti Teknologi MARA, Shah Alam Campus,40450, Selangor, Malaysia.

lindakeruing@gmail.com, sitir704@.uitm.edu.my, ismai578@uitm.edu.my

\begin{abstract}
The designated learning environment should be created as a unique learning space for autistic children and consider the sensory issues to overcome their needs. This learning environment would help Autism Spectrum Disorder (ASD) to continue their education in different environments to survive independently in the real world. This study used the variables of sensory stimulation, sensory sensitivity, sensory design, and physical learning environment to construct a questionnaire. It would distribute to architects towards achieving their level of knowledge and awareness. Findings are useful in the future for architects and designers when making decisions to provide conducive facilities for the autistic.
\end{abstract}

Keywords: Sensory stimulation; sensory sensitivity; sensory design; physical learning environment

eISSN 2514-7528 @2019 The Authors. Published for AMER, ABRA \& cE-Bs by e-International Publishing House, Ltd., UK. This is an open access article under the CC BY-NC-ND license (http://creativecommons.org/licenses/by$n c-n d / 4.0 /$ ). Peer-review under responsibility of AMER (Association of Malaysian Environment-Behaviour Researchers), ABRA (Association of Behavioural Researchers on Asians) and $c E-B s$ (Centre for EnvironmentBehaviour Studies), Faculty of Architecture, Planning \& Surveying, Universiti Teknologi MARA, Malaysia.

DOI https://doi.org/10.21834/jabs.v4i14.338 


\subsection{Introduction}

Autism Spectrum Disorders (ASD) is now high profile and has occurred in every nation of the world. The U.S. Centers for Disease Control and Prevention's Autism and Development Disabilities Monitoring (ADDM) Network has identified children with ASD. In 1990 about 1 in 150 children had been identified with ASD, 2012 the ratio is 1 in 68 children has identified, and a 2014 study the statistic has increased 1 in 59 children aged eight were detected (Schaffhauser, 2018). In Malaysia, the Ministry of Health in 2004 found that autism prevalence rates were 1 case for 600 births, with an estimated 13,333 children aged 15 and under are having autism in the country. However, the prevalence rate is closer to the rates in developed countries such as 1 in 68 in the US and 1 in 100 in the UK (Chiam, 2016). With the tremendous in numbers, it gives impact to the country, community, and family. The increasing rate of ASD prevalence is also a great challenge for the education system and needs national efforts to address the problems (Matin, Haghgoo, Samadi, Rassafiani, Bakhshi, Hassanabadi, 2017). Besides, it became a significant challenge to public education because many children with autism required intensive interventions to facilitate their participation and success in the educational setting (Kinnealey, Pfeiffer, Miller, Roan, Shoener, Ellner, 2012).

Architects role and responsibility is to provide a design that responds to the needs of all members of society. Architects need to understand the experience of those who are most sensitive to their surroundings. Rising levels of autism in children bring social anxiety, isolation, and difficulty integrating into typical schooling situations (Denhardt, 2017). The built environment can be overwhelming, alienating, and challenging to negotiate. The sensory and social difficulties characteristic of the disorder would provide the surrounding environment with increased significance as a source of stimulation and distraction. This environment can act as a barrier to learning and obstructing the development of the child (Mcnally, Morris, \& Mcallister, 2013). However, designers are lack of awareness of sensory issues regarding the built environment in the daily life of autism before the designing stage. Any unwanted distraction can impact negatively upon that child's ability to learn (Mcnally et al., 2013; Fulton, Eapen, ÄCErnÄlec, Walter, \& Rogers, 2014; The National Autistic Society, 2015). Once autistic children starting their learning process, the quality of the environment is so much essential and avoid confusing and frustrating to the autistic mind (Beaver, 2006). The learning environment for autism is an extremely complex condition which affects each person differently and can benefit more from the sensory input that the built environment provides (The National Autistic Society, 2015).

Autistic children are encouraged to continue their education in different learning environments to survive independently in the real world. The designated learning environment should be created as a unique learning space for autistic children and consider the sensory issues to overcome their needs. The objective is to construct a questionnaire based on the key concept of sensory stimulation, sensory sensitivity, sensory design, and physical learning environment - the survey distributed to architects towards achieving their level of knowledge and awareness for designing autism spaces. Findings are useful in the future for architects and designers when making decisions to provide conducive facilities for the autistic. 


\subsection{Literature Review}

\subsection{Architectural Brief Writing}

Designing spaces appropriately for people with autism has many challenges. Writing briefs for buildings is difficult, and it is not just a list of rooms with sizes, but it is about the performance of the building in use by the autistic person (Beaver, 2006). In the context of autism, those were cared for, and those are doing caring means both have different needs (Beaver, 2006). Since architects are the creators of built environments, the task for providing appropriate atmospheres for people with autism falls into the realm of architecture (Pomana, 2014). The process of designing the built environment is extremely complex. All the requirements by the client who have complex needs and this difficulty become compounded when these users have communication difficulties (Jenkins, Scott, \& Challen, 2012). In such circumstances, designers need to engage in innovative methods of brief development with the client and often also with the users themselves. Jenkins et al. (2012) mentioned that useful client briefing is now were considered as fundamental to the production of buildings which satisfy not just functional needs but also reflect user preferences concerning the environmental qualities they create. The important of the architectural brief is where architects and contractors have specialist knowledge of the design and construction of the built environment. However, both types have a limited understanding of the range and complexity of autism requirements and their impact upon designed and built spaces and places (Jenkins et al., 2012). Children with ASD often engage in problematic behaviors such as aggression, self-injurious behavior, and stereotyped behaviors, as they easily disrupt during the learning process and other children are at risk and making it very difficult for them to transition to access mainstream education settings (Fulton et al., 2014). This is due to creating responsive buildings for people with ASD are complicated means lacking awareness in terms of sensory design and about how much environment can affect people with autism by architects (Stuart, n.d.; Society, 2015). Most architects, engineers, and building owners have limited knowledge of ASD and often unaware of the need to bring in specialists, where a broad range in sensitivity should consider for each requirement that has different qualities in their surroundings (Stuart, n.d.; Society, 2015). Once space is operated to provide safety and comfort, autistic people will have an easier task in continuing focus in the different interactions that they need to undertake (Pomana, 2014). Indeed, there is essential to think of about designing buildings for autism.

\subsection{The Key Concept}

Many aspects to be considered and spend some times to list the major issues while the key concept related to autism would discuss. This section will explain briefly regarding sensory sensitivity, sensory stimulation, sensory design, and physical learning environment that extremely important for architects to consider in the design.

\subsubsection{Sensory Sensitivity}

Architecture plays a significant role in resolving sensory information to decrease distractions and reduce stressful stimuli that impede the learning process (Yates, Mclaren, \& Proksch, 
2016). The education design plays a critical role in how students with special needs learn, affecting how they occupy and experience their spatial environment (Yates et al., 2016). They also mentioned that autistic might exhibit either hyper or hypo-reactivity to sensory input from the environment. This may include attraction with lights or movement, sensitivity to bright light, or adverse response to certain textures or sounds.

Firstly, Sensory Sensitivity of High Stimulation (Hypersensitive) means overresponsive to sensory stimuli. Children with hypersensitive can be easily overwhelmed with the environment that disturbing at times. Such as loud or sudden noises that would make them feel physically painful (Gaines, Bourne, Pearson, \& Kleibrink, 2016). Some experts believe that this kind of sensory overload is experienced more among individuals with Asperger's syndrome than other individuals on the spectrum (Gaines et al., 2016). Many individuals with ASD experience hypersensitivity to their environments. They have too much information to process by the brain, causing the individual to be extremely responsive. This can result in very overwhelming feelings and can cause stress or pain in environments where others are comfortable (Yates et al., 2016).

Secondly, Sensory Sensitivity of Low Stimulation (Hyposensitive) means underresponsive, as if certain sensory information goes unnoticed or certain senses are impaired (Gaines et al., 2016). Children who diagnose had hyposensitive with auditory tendencies were often thought to be deaf. Hyposensitive are often qualified as "sensory-seeking," meaning they often create or generate their own sensory experiences either for pleasure or to block out other unpleasant stimuli (Gaines et al., 2016). Individuals with ASD can experience hyposensitivity, meaning they process less information than what is usual. For instance, visually, this can mean that specific elements within a space may be interpreted as only outlines (Yates et al., 2016). Both types of sensory sensitivity consist of sight, sound, smell, touch, taste, proprioception, and vestibular.

\subsubsection{Sensory Stimulation}

The sensory stimulation principle relates to how exciting and vibrant the classroom is (Peter Barrett, Fay Davies, Yufan Zhang, 2015). They notified that it has two parameters, which are complexity and color. They also mentioned regarding the color is straightforward, but does involve all the color elements in the room. While the complexity is a measure of how the different elements in the room combine to create a visually coherent and structured, or random and chaotic environment. It has suggested that focused attention is crucially important for learning. Therefore, they stressed that maintaining focused attention in classroom environments may be particularly challenging for young children because the visual features in the classroom may affect their learning development.

According to Liss Radunovich \& Kochert (2014), sensory stimulation is related to unusual responses regarding acoustic, color, smell, lighting, and visual. Autistic may experience a completely different set of responses to a given stimulus than children who do not have autism. The setting for the learning environment should consider the sensory issues to overcome their needs and to help them to continue their lives and exhibit normal development (Beaver, 2006). Classroom lighting can improve student comfort and attention (Kinnealey et al., 2012). Although fluorescent lights are energy efficient it does not provide 
the best quality of light for learning especially for autistic children. According to Kinnealey et al. (2012), fluorescent lights have been associated with increased student stress and may negatively affect students' learning, behavior, and comfort. Unlike the regular classroom that is designed to stimulate the students, space should be designed to reduce sensory stimulation (Hebert, 2003). Also, Hebert (2003) mentioned that the walls were painted soothing colors and were free of busy bulletin boards. The lighting, rather than fluorescent, was soft and free from hanging mobiles and artwork. Space should highly organize, and all materials were in the proper place and accessible to the child, encouraging independence. While Gopal \& Raghavan (2018) suggested that architects should design for maximum air movement to reduce smells and odors. Not only the air movement but also incorporate naturally scented objects in the design such as flowers, flowering plants, or even burning scent. They also mentioned that natural and artificial lighting is to ensure good general lighting for the entire space without the flickering lights or dark corners. For instance, the lighting design for contrasting shadows of design elements/objects and ensure means for clear outside view with due consideration to privacy (Gopal \& Raghavan, 2018). Dull shades of different warm colors are to be used in the design, while curve the edges of walls and surfaces, minimize conflicting visual textures and reflective surfaces but include fractal patterns and natural elements (Gopal \& Raghavan, 2018). Their research also stressed that echo proof through design elements for examples the cloth curtains and bookcases.

The learning environment would become calm and sooth if the environment is to provide for sustained low background sound like water features, wind chimes, and so on (Gopal \& Raghavan, 2018). Autistic children need to be in the calming environment, therefore, designers should provide for the prevention of heat gain in the space through appropriate design of transparent such as the double glazing for fixed windows, shading for openable windows and opaque (false ceiling for heat from roofs) elements (Gopal \& Raghavan, 2018). Finally, researchers as Peter Barrett, Fay Davies, Yufan Zhang (2015) revealed that colors show that room color affects both emotions and physiology causing mood swings that can have an impact on performance toward the autistic child.

\subsubsection{Sensory Design}

Sensory design is design for living which how space feels, sounds, looks, smells, and functions can be incredibly affecting one or more of the seven senses which can have an overwhelming effect on their life (Society, 2015). Research done by Paron-Wildes (2005) explained that when designing children's environments, it is important to consider the needs of children with neurological disorders and to think through space as an experience. The ASPECTSS ${ }^{\mathrm{TM}} \odot$ Design Index sets out by Dr. Mostafa for autism-friendly design. They can be applied on a smaller scale at home, as well as by professionals. The index summarizes the seven design criteria such as acoustics, spatial sequencing, escape space, compartmentalization, transition spaces, sensory zoning, and safety conclusively recommended to facilitate and improve the user-built environment relationship for autistic individuals (Mostafa, 2015). 


\subsubsection{Physical Learning Environment}

The physical component includes all physical aspects such as classrooms, teaching materials, and learning facilities, both inside and outside the classroom (Fraser, 1994; Kilgour 2006). Research done by Shaari \& Ahmad (2016) proved that there is a link between the physical learning environment and children school readiness. Therefore, the importance of the physical learning environment can no longer be ignored. They suggested that a quality and properly-designed physical learning environment will boost the development and education of children as well as contributing to improved school readiness among children and a better education system. Another essential aspect of creating a suitable environment for autistic is spatial guidance. In both outside and inside spaces, navigation through the surroundings should made by establishing clear paths and directions for each function (Pomana, 2014). Hence, ensuring that school children are ready is important when designing a school. The physical learning environment consists of building scale, accessibility, wayfinding, toilet provision, window, ventilation and heating, threshold, legibility, and furniture.

\subsection{Methodology}

The study is ongoing research, and researchers briefly explain the process to construct the research tools. The study objective is to identify how far the government architects awareness and their experiences in developing the design stage for autism. Because the questionnaire is meant to be completed by the architect, it has developed with sign ration at the Autism Centre. It started with several research approaches; chronologically beginning with a concept, it draws from accumulated knowledge, existing theories, and preliminary field survey to formulate the theoretical concept.

\subsection{Research Techniques}

\subsubsection{Literature Review}

A review of the literature is carried out in this research to develop a broad understanding of autism. Using this understanding, variables that significantly affect the autism has identified. The key concepts obtained from various sources. Most of the references are books, journal articles, and other forms of literature that resourced through the e-library, subscription databases, and internet platforms. In managing the literature materials for easy retrieval and cross-reference, this research used Mendeley, which are easy-to-use reference management software. All the identified literature read entirely and thoughtfully. This involved identification of critical arguments, suggestions, methodology, statistical approaches, and areas of concern.

\subsubsection{Case Study Selection}

The case study selected as the approach in this research since there is a distinct need to research a complex phenomenon holistically based on real-life conditions (Yin, 2008). The Pusat Permata Kurnia was chosen as the case study for this research due to two main grounds. First, it is a pioneer autism center and become a benchmark and located in the non- 
urban area. Second, it is early intervention center involves children at the age of four to six years old that facilitated by the government.

\subsubsection{Subjects}

The reference targeted population among the government architects in a technical agency in Malaysia is 345 architects. The study conducted among architects in Building and Specialist Sector at Public Works Department Malaysia, Kuala Lumpur. The chosen sector based on the accessibility and the population that fulfilled the study. Architects in Building and Specialist Sector involve design and managing the project.

\subsubsection{Development of Tool}

The process to construct the questionnaire for the study mostly derives from EnvironmentBehavior research methods, discussed by (Khare \& Mullick, n.d.). The concept that drives the entire research is 'an architect's knowledge of sensory sensitivity, sensory stimulation, sensory design, and physical learning environment for designing the Autism Centre.' This concept creates from researcher's experiences during preliminary exploration and the literature on autism. In the first phase of the study, extensive initial investigation is carried out to deepen the understanding of the concept. This elaborate research stage in the present study derives from available literature on previous works. The literature on autism regarding the sensory sensitivity and sensory stimulation (Hebert, 2003; Beaver, 2006; Liss Radunovich \& Kochert, 2014; Gaines, Bourne, Pearson, \& Kleibrink, 2016; Gaines et al., 2016). The second phase of the study is adopted to establish the existing theories of sensory design and physical learning environment for autism (Fraser, 1994; Paron-Wildes, 2005; Kilgour 2006; Society, 2015; Mostafa, 2015; Shaari \& Ahmad, 2016).

\subsubsection{Measures}

The researcher construct the questionnaire with overall 145 items in four section of the study, there are (1) Sensory Sensitivity consist of sight, sound, smell, touch, taste, proprioception and vestibular; (2) Sensory Stimulation consist of acoustic, colour, smell, lighting and visual; (3) Sensory design consist of the seven design criteria such as acoustics, spatial sequencing, escape space, compartmentalization, transition spaces, sensory zoning, and safety; (4) Physical learning environment consists of building scale, accessibility, wayfinding, toilet provision, window, ventilation and heating, threshold, legibility, and furniture.

\subsubsection{Reliability and Validity}

The final phases of the research focused pre-test on formal reliability and validity testing in a questionnaire. Pre-tests used as a way to judge the depth of understanding of essential material (Berry, 2008). Development and testing of the scale and its subscales have involved extensive reliability and validity testing through a professional architect, expert panels, and related field research. Content validity is the extent to which a test or measure provides an adequate representation of the degree to which the items are judged necessary and valid by the experts. Construct validity is the degree to which the scale as a whole is a good measure of the sensory sensitivity, sensory stimulation, sensory design and physical learning 
environment for autism (Moore \& Sugiyama, 2007).

\subsection{Procedure}

The ethical issues considered to maintain the participants' confidentiality and privacy in the research conducted. The ethical permission shall obtain from the administration of the Public Works Department Malaysia. The participants will be given a set of questionnaire and inform consent to explain briefly about the nature of the study to enable the participants to decide on taking part in the survey. The autonomy of the participants also emphasized in the consent. Data will be collected through a questionnaire distributed to the architects. The participant must answer and respond to all questions on the survey. The completed questionnaire will be collected from the participants, and finally, all the information about the participant is kept confidential.

\subsection{Conclusion and Discussion}

The classrooms attended by autistic children are highly interactive and unpredictable environments, even when the daily activities have been carefully arranged (Martin, 2014). Therefore, designing for spaces in which the autistic child could be sensorily, comfortable, and can potentially help the teachers as many of the symptoms could be an exhibit of their sensory discomfort. It could reduce parenting stress and can be empirically analyzed through pre-intervention and post-intervention survey of caregiver stress (Martin, 2014). Hence designers should be aware to overcome the sensory issues at an early design stage for sensory discomfort. This might help to reduce the sensory issues related to impairment in social interaction and communication in autistic children. It is hoped that this ongoing research would accumulate a body of knowledge and to produce a supportive environment for children with autism. We strongly believe that the conducive environment is expected to influence peoples to behave. Designing an environment for children with autism is a great challenge among architects. Not only to create conducive environment but also the building must be warm and friendly, provide an environment with enough space that allows independence and is fun to live in. The researchers expectation that the questionnaire would give the response and awareness from architects regarding the sensory stimulation (lighting, smell, colour and visual), sensory sensitivity (sight, sound, smell, taste, touch, proprioception, vestibular), sensory design (acoustic, compartmentation, spatial sequencing, thresholds, escape space, sensory zoning, safety, and security) and physical learning environment (accessible, wayfinding, scale, toilet accommodation, ventilation, window, quiet room, legibility and furniture) that are the essential features attributes to conducive learning environment. The research process adopted in the present study employs architects in an orderly way, to achieve the research objectives and to design supportive, accessible and lastly inclusive environment that shows all children that they are valued members of our society and their contributions are essential. Thus it is useful for architects and designers, service providers, and policymakers of special needs for autistic learning environment when making decisions to provide conducive facilities for the autistic. These key aspects for creating autistic friendly environments improve both the lifestyle of people with autism, but 
are also beneficial for all people that navigate the public space (Pomana, 2014). The study also expected that the proposed framework would help them informing the scope and brief design before the designing stage and it is hoped that it would intend to get an idea of what designers can take it from understandings of 'other' perspective on the built environment. As architects or designers, it is essential for them to create the learning environment not only within the classroom but also to integrate the other additional area with unique ideas into the autistic center. With design based researchers suggested that to create different spaces that foster inclusive and fun places for autistic children to enjoy and live in. This can ultimately help autistic to focus during their learning process, although having different abilities.

\section{Acknowledgment}

I would like to thank my supervisor Dr. Siti Rasidah Md Sakip and Asso. Prof. Dr. Ismail Samsuddin for supporting me. Also, I would thank Jabatan Kerja Raya Malaysia for allowing me to further my study.

\section{References}

Beaver, C. (2006). Designing Environments for Children \& Adults with ASD. Autism Safari 2006 2nd World Autism Congress \& Exhibition.

Berry, T. (2008). Pre-Test Assessment. American Journal of Business Education -, 1(1), 19-22.

Chiam, M. (2016, April 18). Stepping Up. The Star.

Denhardt, T. (2017). Autism-aware design | Architecture Now. Autism-Aware Design | Architecture Now, (4), 1-9. Retrieved from http://architecturenow.co.nz/articles/autism-aware-design/\#img=6

Fulton, E., Eapen, V., ÄCErnÄlec, R., Walter, A., \& Rogers, S. (2014). Reducing Maladaptive Behaviors in Preschool-Aged Children with Autism Spectrum Disorder Using the Early Start Denver Model. Frontiers in Pediatrics, 2(May), 1-10. https://doi.org/10.3389/fped.2014.00040

Gaines, K., Bourne, A., Pearson, M., \& Kleibrink, M. (2016). Designing for Autism Spectrum Disorders. New York: Routledge Taylor \& Francis Group. https://doi.org/10.4324/9781315856872

Gopal, A., \& Raghavan, J. (2018). Design interventions for Sensory comfort of Autistic children. Autism-Open Access, 08(01), 1-8. https://doi.org/10.4172/2165-7890.1000227

Hebert, B. B. (2003). Design Guidelines of a Therapeutic Garden for Autistic Children. Louisiana State University. Jenkins, P., Scott, I., \& Challen, A. (2012). Client Briefing: Eliciting Design Preferences from Building Users with Communication Impairments. Buildings, 2(2), 83-106. https://doi.org/10.3390/buildings2020083

Khare, R., \& Mullick, A. (n.d.). Universally Beneficial Educational Space Design for Children with Autism ; the Research Progression.

Kinnealey, M., Pfeiffer, B., Miller, J., Roan, C., Shoener, R., \& Ellner, M. L. (2012). Effect of classroom modification on attention and engagement of students with autism or dyspraxia. American Journal of Occupational Therapy, 
66(5), 511-519. https://doi.org/10.5014/ajot.2012.004010

Liss Radunovich, H., \& Kochert, J. L. (2014). Creating a Successful Early Learning Environment for Children Who Have Autism Spectrum Disorders 1 What Are Autism Spectrum Disorders? In IFAS Extension (pp. 1-6).

Martin, C. S. (2014). Exploring the impact of the design of the physical classroom environment on young children with autism spectrum disorder (ASD). Journal of Research in Special Educational Needs, 16(4), 280-298. https://doi.org/10.1111/1471-3802.12092

Matin, N., Phd, S., Allah, H., Phd, H., Ali, S., Phd, S., ... Phd, H. H. A. (2017). The Impact of Dynamic Seating on Classroom Behavior of Students with Autism Spectrum Disorder. 29 Iran J Child Neurol. WINTER Iran J Child Neurol. Winter, 11(111), 29-36. Retrieved from https://www.ncbi.nlm.nih.gov/pmc/articles/PMC5329757/pdf/ijcn 11-029.pdf

Mcnally, H., Morris, D., \& Mcallister, K. (2013). Experiencing Primary School through the lens of the autistic spectrum. Aldo goes to Primary School. (D. M. \& K. M. A. Hugh McNally, Ed.). McNally Morris Architects.

Moore, G. T., \& Sugiyama, T. (2007). The Children's Physical Environment Rating Scale (CPERS): Reliability and Validity for Assessing the Physical Environment of Early Childhood Educational Facilities. Children, Youth \& Environments, 17(4), 24-53. https://doi.org/10.7721/chilyoutenvi.17.4.0024

Mostafa, M. (2015). An Architecture for Autism: Built Environment Performance in Accordance to the Autism ASPECTSS ${ }^{\mathrm{TM}}$ Design Index. Design Principles and Practices: An International Journal-Annual Review, 8(1), 55 71. https://doi.org/10.18848/1833-1874/CGP/v08/38300

Paron-Wildes, A. J. (2005). Sensory Stimulation and Autistic Children. Implications, 06(04), 1-5.

Peter Barrett, Fay Davies, Yufan Zhang, L. B. (2015). The impact of classroom design on pupils' learning\&quot; Final results of a holistic, mulit level analysis, 89. Retrieved from https://ac.els-cdn.com/S0360132315000700/1 s2.0-S0360132315000700-main.pdf?_tid=93dfa965-74bf-4215-94c3 91f840d9da86\&acdnat=1521225988_3f7769d92bf69c41e45935f4c8e81cb7

Pomana, A. (2014). Architecture For Autism; Improving Designs for Autistic Integration, 1-197. Retrieved from http://icar2015.uauim.ro/dld/cd/ICAR2015_Section_3_Archive-Utopia-Events_Built-Unbuilt.pdf

Schaffhauser, D. (2018). Sensory Room Provides Focus for Autistic Students. THE Journal -Special Needs. Retrieved from file:///C:/Users/User/Dropbox/ORGANIZER/AUTISM/sensory design/Sensory Room Provi des Focus for Autistic Students -- THE Journal.html

Shaari, M. F., \& Ahmad, S. S. (2016). Physical Learning Environment: Impact on Children School Readiness in Malaysian Preschools. Procedia - Social and Behavioral Sciences, 222, 9-18.

https://doi.org/10.1016/j.sbspro.2016.05.164

Society, T. N. A. (2015). Autism Friendly Design. Your Autism Magazine, 49(2), 513600-513600. Retrieved from http://www.autism.org.uk/professionals/others/architects/autism-friendly-design.aspx

Stuart, S. (n.d.). Why Buildings for Autistic People Are Better for Everyone.

The National Autistic Society. (2015). Autism-friendly design. The National Autistic Society, 49(2). Retrieved from http://www.autism.org.uk/professionals/others/architects/autism-friendly-design.aspx

Yates, M., Mclaren, B., \& Proksch, G. (2016). Building Better Schools: A New Model For Autism Inclusion in Seattle. 